\title{
Clinical application of regional lung function studies in infants and small children using ${ }^{13} \mathrm{~N}$
}

\author{
R. RONCHETTI^, JANET STOCKS, NANETTE FREEDMAN, H. GLASS $†$, and \\ S. GODFREY \\ From the Department of Paediatrics and Neonatal Medicine, and Department of Medical \\ Physics, Hammersmith Hospital, London
}

\begin{abstract}
Ronchetti, R., Stocks, J., Freedman, N., Glass, H., and Godfrey, S. (1975.) Archives of Disease in Childhood, 50, 595. Clinical application of regional lung function studies in infants and small children using ${ }^{13} \mathbf{N}$. A technique is described for the investigation of regional lung function in infants and children using ${ }^{13} \mathrm{~N}$ and a gamma camera. Boluses of isotopic gas are inhaled and perfused while the lung fields are scanned. The child is lightly sedated and breathes normally throughout. Regional function is assessed in terms of the distribution of gas and blood, and the balance between ventilation and perfusion is estimated by comparing an index of the ventilation per unit volume of ventilated lung with that of perfused lung. The use of the method in 8 infants and children with different clinical problems is described to show its application. The method is capable of defining the severity and localization of any abnormality and may also be useful in showing normal function in suspect areas.
\end{abstract}

Respiratory disease is a major cause of morbidity and mortality during infancy and early childhood. Great advances have been made over the years in developing methods for measuring lung function in infants analogous to those used in adults, and normal ranges have been defined (Godfrey, 1974). These tests are only practicable during the first few months of life when the infant can be lightly sedated and studied without active co-operation. Above this age the infant or small child is very liable to resist any attempts to measure breathing and such studies are virtually impossible without anaesthesia until about 5 years of age. Unfortunately, a number of conditions present or progress in this period of 6 months to 5 years when children are least accessible. Moreover, conventional lung function tests or blood gas measurements can only assess total lung function, and give no clues as to regional variations in function which may be clinically important.

In adults it is now routine practice to assess regional lung function after inhalation and infusion of radioactive gases such as xenon $\left({ }^{133} \mathrm{Xe}\right)$. Origin-

Received 20 January 1975.

Present addresses: ^Department of Paediatrics, University of Rome, Italy. †NW Regional Health Authority, London W2. ally such measurements were made with several external counters (Knipping et al., 1955), but more recently a gamma camera has been used (SeckerWalker et al., 1973). Some preliminary work has been carried out in healthy and sick infants (Ronchetti et al., 1971; Koch et al., 1973), and recently a more definitive method of using ${ }^{133} \mathrm{Xe}$ in children has been described giving some normal data (Treves et al., 1974). We decided to develop the use of radioactive nitrogen $\left({ }^{13} \mathrm{~N}\right)$, which has a halflife of 10 minutes, because of its lower solubility in tissue and fat compared with xenon which renders it more suitable for studying lung function in infants and children with pulmonary problems. The method has been designed so that active co-operation is not needed. We present the results of our initial studies in 8 infants and children where the method proved to be of considerable clinical value.

\section{Subjects and methods}

The 8 children, who were all undergoing investigation or treatment were between 2 weeks and $2 \cdot 2$ years old; one child was studied twice during his illness. Some clinical details of the patients are given in Table I. A variety of problems was studied, each baby being investigated to help establish the diagnosis or severity of 
TABLE I

Details of patients

\begin{tabular}{|c|c|c|c|}
\hline \multirow{2}{*}{ Case no. } & \multirow{2}{*}{ Diagnosis } & \multicolumn{2}{|c|}{ At time of study } \\
\hline & & Age & Weight (kg) \\
\hline $\begin{array}{l}1 \\
2 \\
3 \\
4 \\
5 \\
6 \\
7 \\
7\end{array}$ & $\begin{array}{l}\text { Agenesis of the } R \text { lung } \\
\text { Cystic lesions of lung with generalized } \\
\text { hyperinflation and Fallot's tetralogy } \\
\text { Pulmonary hyperinflation, airway } \\
\text { obstruction, Macleod's syndrome } \\
\text { Cystic fibrosis } \\
\text { Atypical arthrogryposis with kyphoscoliosis } \\
\text { Possible congenital lobar emphysema with } \\
\text { collapse of } R \text { upper lobe } \\
\text { Alveolar hypoplasia } \\
\text { Wilson-Mikity syndrome }\end{array}$ & $\begin{array}{l}2 \mathrm{w} \\
\text { (a) } 5 \mathrm{w} \\
\text { (b) } 6 \cdot 5 \mathrm{~m} \\
\\
26 \mathrm{~m} \\
8 \mathrm{w} \\
24 \mathrm{~m} \\
9 \mathrm{w} \\
11 \mathrm{w} \\
5 \mathrm{~m}\end{array}$ & $\begin{array}{r}2 \cdot 1 \\
3 \cdot 0 \\
5 \cdot 6 \\
11 \cdot 0 \\
3 \cdot 6 \\
7 \cdot 5 \\
3 \cdot 5 \\
5 \cdot 6 \\
2 \cdot 6\end{array}$ \\
\hline
\end{tabular}

the conditions listed in Table I. ${ }^{13} \mathrm{~N}$ was produced by the Medical Research Council Cyclotron Unit and piped to a dispensing laboratory adjacent to the room where the gamma camera was situated. The desired quantity of radioactivity was made up as a gas or dissolved in sterile isotonic saline $(0.1-0.5 \mathrm{mCi} / \mathrm{ml}) \mathrm{im}$ mediately before use. During and after inhalation or intravenous administration of the radioisotope, the lungs were examined continuously with the gamma camera for 5 minutes, and the data stored on digital magnetic tape and subsequently processed by computer (Fig. 1). The data were corrected for physical decay of the radioisotope and for the natural background count-rate. The count-rates at selected time intervals were then shown on an oscilloscope and presented graphically. The computer program allowed considerable automation of the data processing. Of particular advantage was the availability of a light pen and oscilloscope which allowed selected regions of any shape to be delineated within the lung fields and the appropriate count-rate versus time curves to be obtained easily for each selected region of the lung.

The smaller infants were lightly sedated with chloral hydrate $(30 \mathrm{mg} / \mathrm{kg})$ and studied after a feed, while the older babies usually received diazepam as premedication. The patient lay supine over the gamma camera and was made comfortable so that he dozed off or lay quietly. The position of the infant was checked with a radioisotope marker in all but the earliest studies. In order to inject ${ }^{13} \mathrm{~N}$ intravenously, a scalp vein needle was inserted in the smaller infants and a needle was placed in an arm vein in the older infants. A continuous infusion of dextrose-saline was used to keep the line patent until the injection was given. For the inhalation study we initially used a hood placed over the head through which a stream of test gas was blown. In later studies we found it more satisfactory to inject the gas through a nasal catheter passed back as far as the nasopharynx. The babies tolerated both the intravenous and the nasal catheter well and breathed spontaneously throughout.

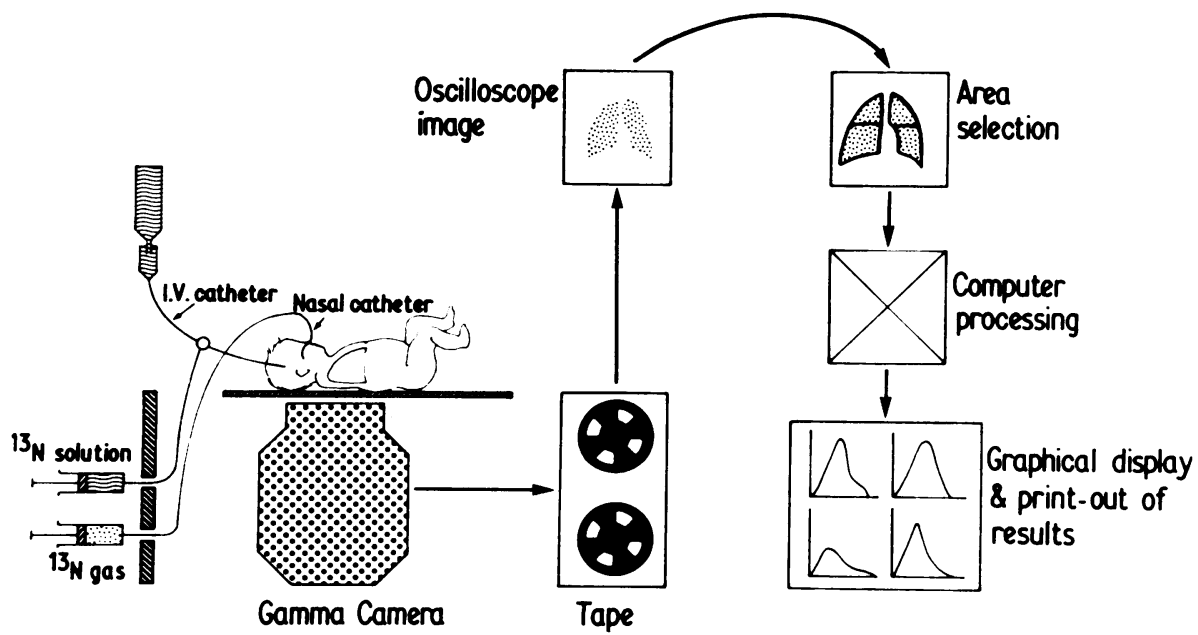

Frg. 1.-Diagram illustrating general principles of technique of ${ }^{13} \mathrm{~N}$ studies. 
During the studies, expired radioactive gas was expelled to the outside air by means of a simple pump and widebore tube placed close to the baby's face.

For each infant ${ }^{13} \mathrm{~N}$ was given once by inhalation and once by infusion with a suitable time period between each procedure to allow all the residual radioactivity to clear. In the initial studies an attempt was made to deliver the gas for each test at a constant rate for one minute as suggested by Ronchetti et al. (1974), but it was apparent from the records that this gave an inadequate count-rate for subsequent data analysis. The highest count-rates were observed after the catheters were eventually flushed through with air or saline, effectively delivering a bolus of gas. This procedure was therefore abandoned and a bolus of gas was administered in the six later studies. The inhalation bolus ( $4 \mathrm{ml}$ gas) was delivered into the nasopharynx at the end of an expiration and the infusion bolus was injected as rapidly as possible $\left(4 \mathrm{ml}{ }^{13} \mathrm{~N}\right.$ 'dissolved' in saline delivered over approximately 2-3 s). The dose of radioactivity was calculated on the basis of $0.3 \mathrm{mCi} / \mathrm{kg}$ entering the lungs for each inhalation or perfusion study up to a maximum of $2 \mathrm{mCi}$. The total calculated radiation received by the lungs for a combined inhalation and perfusion study was $180-200$ mrads for infants and approximately $100-130$ mrads for older children. The maximum tissue doses allowing for the worst case of a $50 \%$ right-left shunt were $<25$ mrads. This compares favourably with other isotopic studies used in children (Seltzer, Keriakes, and Saenger, 1964), and with diagnostic radiology such as bronchography which results in about 3 times as much irradiation. No infants appeared to suffer any ill-effects from the study.

\section{Calculation of results}

As the method was evolved during the course of the investigation, a number of different approaches to analysing the data were examined, but finally a simple and practical line was adopted which took account of the poor quality of the earlier data and made the minimum number of assumptions. Essentially we calculated indices of regional distribution of inspired gas ('gas distribution') and distribution of pulmonary blood flow ('blood distribution') from the relative peak count-rate in each region selected for study (Heckscher, Larsen, and Lassen, 1966). The peak count-rate was divided by the actual area of the lung region measured from the oscilloscope screen in order to make some allowance for the relative sizes of different areas. On this basis each regional index was calculated as follows,

\section{Distribution Index $=$

$\frac{\text { Regional Peak Count }}{\text { Whole Lung Peak Count }} \div \frac{\text { Regional Area }}{\text { Whole Lung Area }}$

and hence if blood or gas were uniformly distributed to all regions, the distribution index in each region would be $1 \cdot 0$.

In addition, we obtained an indication of the regional ventilation per unit volume after the manner of Secker-
Walker et al. (1973) by dividing the regional peak height by the area under the subsequent curve of the washout of radioactivity, though the method by which we were obliged to obtain the data prevented us from obtaining these quantities in absolute terms as described by Secker-Walker and his colleagues. For the calculation, the area under the curve was measured to the point where the counts had fallen to $1 \%$ of the peak counts. With the inhalation study this calculation gives an index of the regional ventilation/perfusion ratio of perfused lung, while for the infusion study it gives an index of the regional ventilation perfusion ratio of perfused lung. Any discrepancy between these indices in any given region was taken to indicate an imbalance between ventilation and perfusion of the lung. The indices are similar in concept to those described by Treves et al. (1974).

\section{Results}

The individual values for the calculated indices for each baby are given in Table II. As each patient presented a different problem, each study will be briefly described.

Case 1. Was one of monozygotic twins and clinically and radiologically appeared to have agenesis of the right lung (Fig. 2). A ${ }^{13} \mathrm{~N}$ scan confirmed the absence of any perfused lung tissue on the right and an even distribution of blood to the left (and only) lung. The ventilation of this perfused lung tissue was normal (see below). The inhalation study was technically unsatisfactory. 14 weeks after the investigation the infant died a cot death and necropsy confirmed pulmonary agenesis.

Case 2. The second infant to be studied will be described in detail elsewhere (Godfrey et al., 1975). He had Fallot's tetralogy of a mild degree but radiological evidence of cystic lesions, especially at the lung bases (Fig. 3). The possibility of a localized congenital abnormality was considered and a ${ }^{13} \mathrm{~N}$ scan was carried out at the age of 5 weeks. Both inhalation and perfusion studies had poor count rates but showed relatively even distribution indices. There was extremely poor ventilation of perfused lung compared to ventilated lung, confirming generalized abnormality with gas trapping. Subsequently this infant was restudied at the age of $6 \frac{1}{2}$ months using the improved bolus technique. The results for the ventilation of perfused lung were similar and the difference between ventilation of ventilated lung and the ventilation of perfused lung was even more striking and can be seen in the shape of the respective washout curves (Fig. 4). Though the upper zones were relatively less affected than the other zones (Table II) the 
TABLE II

Individual results of ${ }^{13} \mathrm{~N}$ scan

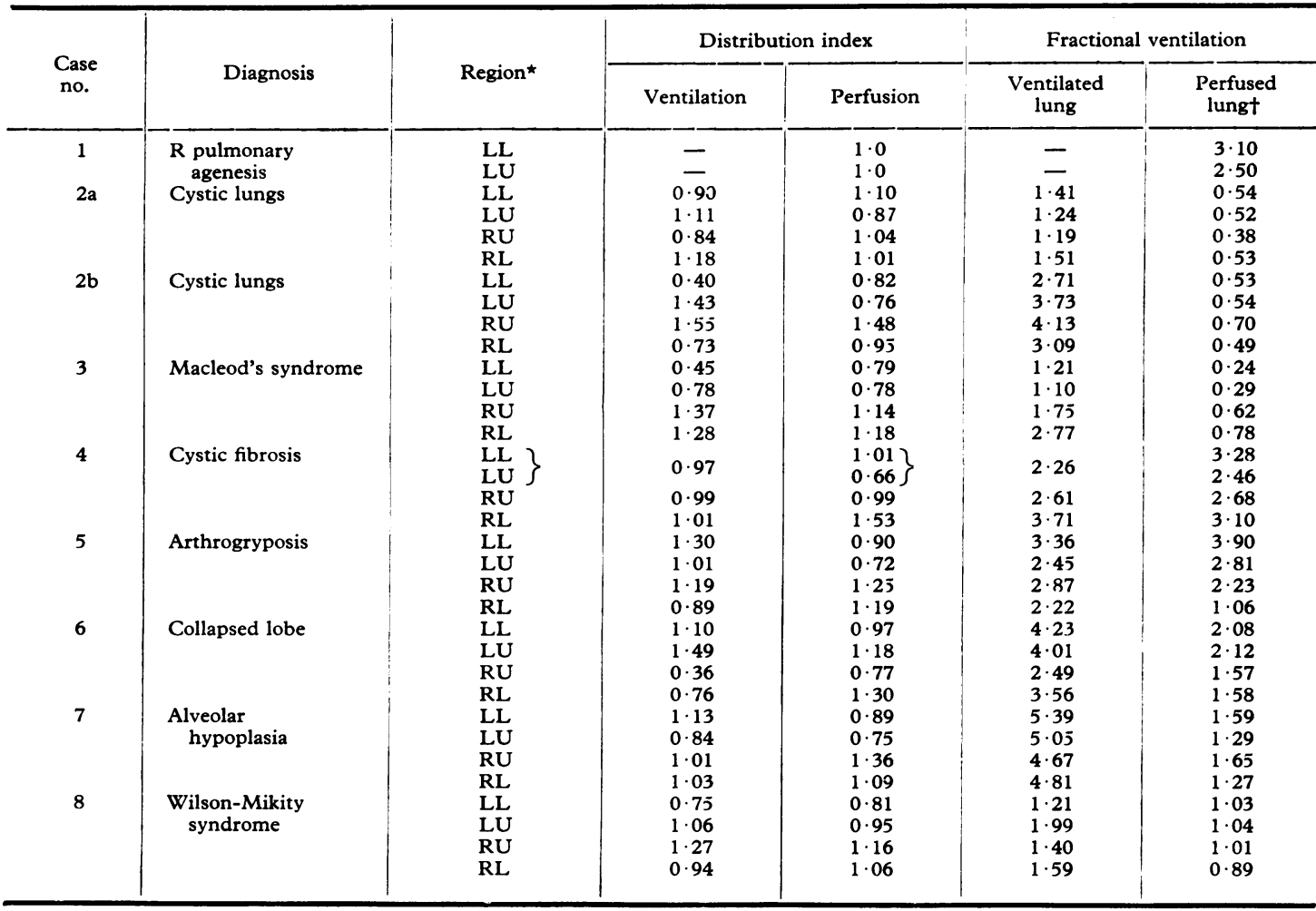

${ }^{\star}$ LL, left lower zone; LU, left upper zone; RL, right lower zone; RU, right upper zone.

tThis is a combination of fractional ventilation and perfusion.

diffuse nature of the disease precluded the possibility of a surgically treatable lesion.

Case 3. This infant was referred for study because of unexplained pulmonary hyperinflation and fixed airways obstruction, thought to be related to previous bronchiolitis. The study showed a marked discrepancy between the right and left lungs, with nearly twice as much gas and blood going to the right. Ventilation of ventilated and perfused lung was also better on the right but poor in all areas, especially for perfused lung. These findings suggested the presence of Macleod's syndrome (Macleod, 1954) which had not previously been suspected. The abnormality predominantly affected the right lung but there was generalized damage to both lungs as a result, presumably, of the bronchiolitis.

Case 4. This infant had meconium ileus due to cystic fibrosis but had not yet had any radiological evidence of lung damage at the time of the ${ }^{13} \mathrm{~N}$ scan The inhalation study was poor because of bad positioning and only one region on the left could be defined. Both inhalation and perfusion studies appeared to be normal except that there was some inequality in the regional distribution of perfusion. The study confirmed the absence of significant pulmonary involvement.

Case 5. This male was 2 years old at the time of study and had atypical arthrogryposis with kyphoscoliosis making regional localization difficult. It was thought that his right lung was underperfused. The ${ }^{13} \mathrm{~N}$ study showed an uneven pattern in which the only definite abnormality was poor ventilation of perfused lung at the right base. Underperfusion of the right lung could not be substantiated.

Case 6. A female was born at 34 weeks' gestation and had the respiratory distress syndrome from 
Clinical application of regional lung function studies using ${ }^{13} \mathrm{~N}$

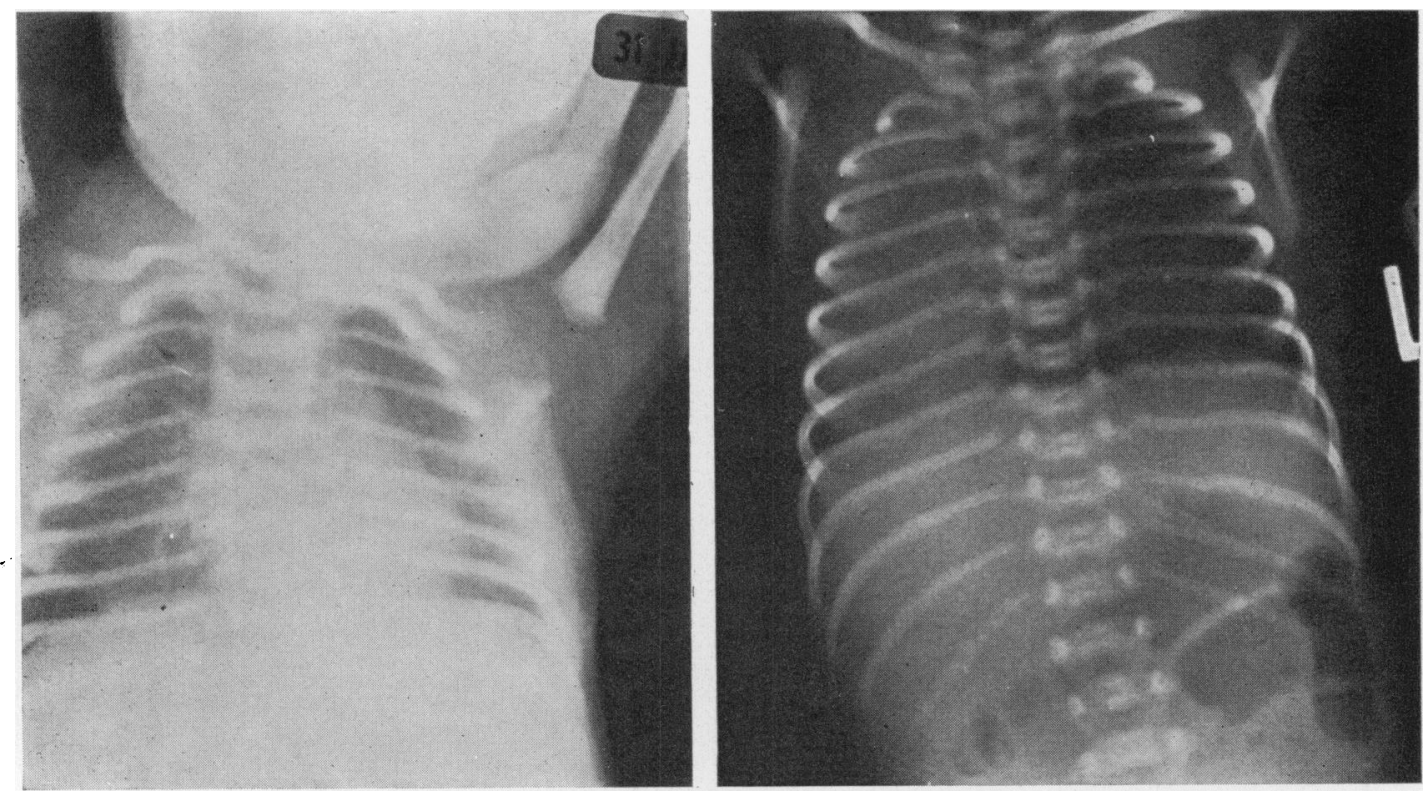

Fig. 2.-X-rays of monozygotic twins. Twin on the right, Case 1, had agenesis of the right lung and was studied by the ${ }^{13} \mathrm{~N}$ technique.

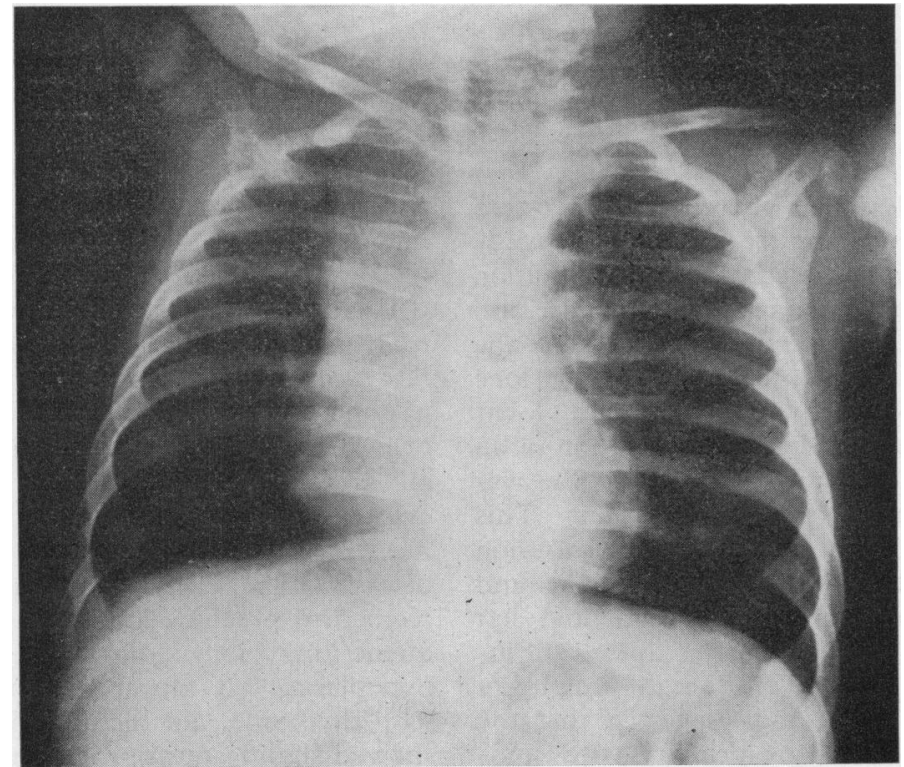

FIG. 3.-Case 2. Chest x-ray of infant with hyperinflated lungs and radiolucent areas especially at the bases, together with Fallot's tetralogy. 


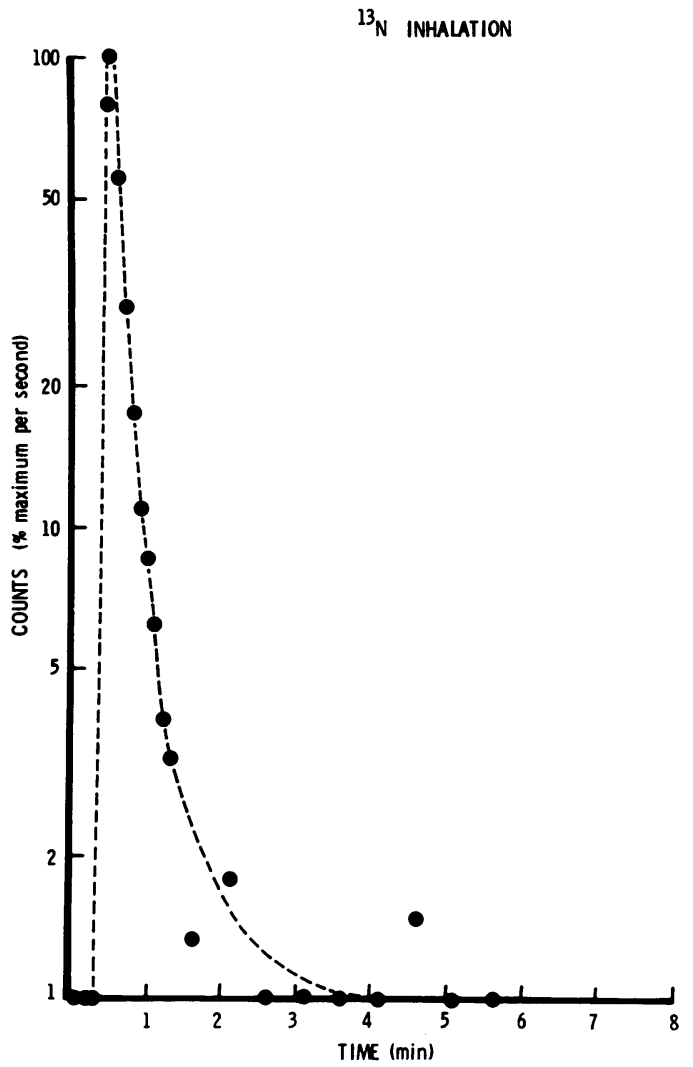

(a)

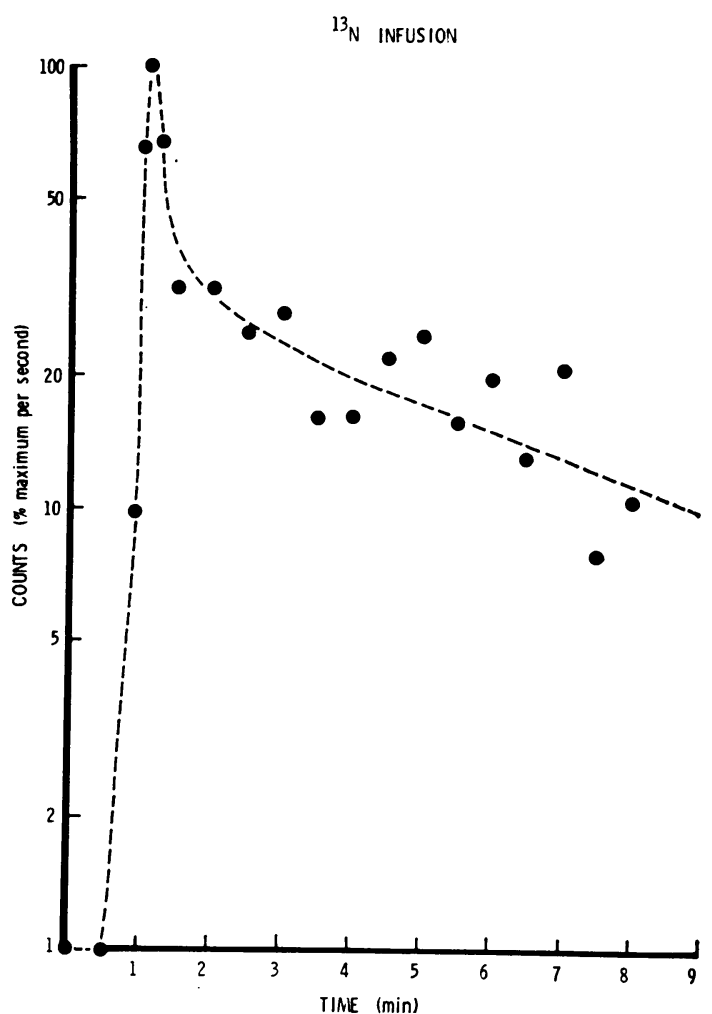

(b)

Fig. 4.-Case 2. Whole lung scans after (a) inhalation (b) and infusion of ${ }^{13} \mathrm{~N}$ in child with hyperinflated cystic lungs. Clearance of activity is much faster after inhalation than after infusion, indicating poor mixing of gases and blood in the lungs.

which she recovered after $0_{2}$ therapy. At 5 weeks of age she had an acute respiratory illness, possibly due to aspiration, and needed artificial ventilation for 48 hours. She remained tachypnoeic and chest $x$-rays showed persistent overinflation of the left upper lobe and collapse of the right upper lobe (Fig. 5). The possibility of congenital lobar emphysema was considered and the question of an exploratory thoracotomy was discussed. She was referred for a preliminary ${ }^{13} \mathrm{~N}$ investigation. This gave unequivocal evidence of reduced distribution of gas and blood to the right upper zone and entirely normal function of the overinflated left upper lobe (Table II). Clearly, this was incompatible with compression of the right lung by an emphysematous left lung, and suggested that the collapse on the right was the primary with compensatory overdistension of the normal left lung. The baby was treated by vigorous physiotherapy and the right upper lobe re-expanded with concomitant return of the left lung to a normal size.

Case 7. A baby of 11 weeks with hypothyroidism and hypoxia of uncertain aetiology. The ${ }^{13} \mathrm{~N}$ scan showed relatively even distribution of gas and blood, but a markedly reduced ventilation of perfused lung compared with ventilated lung in all areas (Table II). This was interpreted as evidence for very poor ventilation-perfusion matching which would be expected with interstitial lung disease. The excellent washout of inhaled ${ }^{13} \mathrm{~N}$ seemed to preclude any airway disease. A subsequent lung biopsy showed generalized pulmonary hypoplasia. (A repeat ${ }^{13} \mathrm{~N}$ study after treatment with thyroxine, not included in the present series, showed significant improvement.)

Case 8. A preterm infant with mild respiratory 


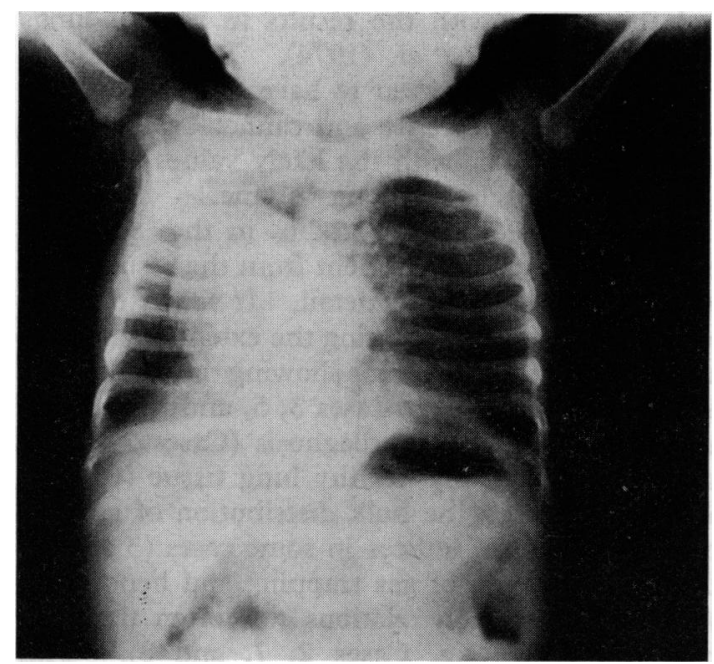

Fig. 5.-Case 5. Chest $x$-ray of infant with hyperinflation of the left upper lobe apparently causing mediastinal deviation and compression of right lung.

distress syndrome at birth who went on to develop clinical and radiological features suggestive of the Wilson-Mikity syndrome though the referring hospital questioned whether the changes could have been secondary to localized infection. Regular lung function tests had shown hyperinflation and increased airways resistance. As in the previous patient, the ${ }^{13} \mathrm{~N}$ investigation showed a relatively even distribution of gas and blood but with ventilation-perfusion imbalance shown by the very poor ventilation of perfused lung. Unlike the previous baby, the ventilation of ventilated lung was also relatively poor, suggesting generalized lung and airway disease. The widespread nature of the changes would not be compatible with local damage from infection and strongly supported the diagnosis of the Wilson-Mikity syndrome.

\section{Discussion}

We believe that the ${ }^{13} \mathrm{~N}$ technique was useful in the diagnosis and evaluation of function in the 8 infants described.

Radioisotopic evaluation of lung function in adults is an established procedure. They are normally studied after rebreathing in order to equilibrate all areas (Secker-Walker et al., 1973) and to correct the results for the volume of lung being viewed (Ball et al., 1962). A similar approach has been used in children (Treves et al., 1974), but their technique must require 2 or 3 minutes of rebreathing through a face-mask though no details are given and they do not describe how they obtained the necessary co-operation. We elected to make measurements during spontaneous respiration in order to have a simpler and practical test able to furnish high counts with small doses of radioactivity. We initially tried to achieve steady state conditions with relatively short inhalations and perfusions, but this method did not give satisfactory count-rates with the dose of radioactivity which we were prepared to use at the time. It could well be argued that steady state inhalation would provide a better index of the function of ventilated lung than a bolus inhalation and might give a better measure of lung volume than the area of the oscilloscope image. Based on our present experience we hope to explore a suitable steady state inhalation procedure. When using bolus injections (Heckscher et al., 1966) the shape of the input function of the bolus arriving at the region of the lung which is being examined is not certain and some radioactivity is removed by ventilation while the latter part of the bolus is still arriving. Though exact analysis of the bolus infusion data is complicated, nevertheless the amount of radioactivity lost by ventilation during arrival of the bolus over a few seconds is probably very small and will hardly influence the results.

The mathematical quantitation of the results in the present study is subject to the limitations mentioned above, but for clinical purposes it seemed adequate to treat all the data in this way. Exponential analysis of washout curves (Fowler, Cornish, and Kety, 1952) has been used in many radioisotope studies of lung function, but this requires the subdivision of the lungs into arbitrary 'slow' and 'fast' compartments, and may be associated with significant errors (Glass and de Garreta, 1971). The fractional ventilation index which we used has the advantage of providing an indication of the total function of each region in terms of the average regional ventilation per unit volume. Within the limits discussed we believe this to be an acceptable approach. The distribution indices based on peak heights are also an approximation since they depend upon the volume of lung in each region. The use of the area of the oscilloscope picture of the region is a relatively poor substitute, but not unreasonable when it is realized that the thinner upper portion of the upper zone is more or less equivalent to the thinner lower portion of the lower zone around the dome of the diaphragm. In fact the results which we got in normal regions of lung seem to justify the method, at least for clinical purposes, and they resemble the distribution indices corrected for volume used by 
Treves et al. (1974). The same regions should be used for both the ventilation and the perfusion studies if possible so that comparisons can be made.

It is possible that the use of an area overestimates volume in diseased regions where the overall size of the lung is retained (e.g. bronchiectasis), but this becomes a semantic problem in the sense that our index then gives the distribution of blood per unit 'volume' of tissue, which will be low, rather than per unit volume of gas-filled lung. Clearly both types of result could well be of use, and we hope to explore this in the future. The fractional ventilation is of course entirely independent of the volume measurement.

The distribution index for inhaled gas is related to the fractional ventilation of ventilated lung because both must reflect regional ventilation. However, the distribution index after injection reflects pulmonary blood flow, while the fractional ventilation of perfused lung is related to the balance between ventilation and perfusion. When gas trapping is present, the ventilation study usually results in a smaller visible area than the perfusion study, and errors would occur if this smaller area were used, because it would exclude some lung tissue which was perfused but poorly ventilated.

We did not consider it acceptable to carry out studies in healthy infants and so we do not have any normal values. However, because of the localized nature of the disease in some of the infants, it has been possible to calculate the fractional ventilation for apparently healthy regions of ventilated and perfused lungs. The value of the mean ventilation per unit volume index for 5 'healthy' ventilated regions was $4 \cdot 27$ (range $3 \cdot 36-$ $5 \cdot 05$ ), and the fractional ventilation index for 'healthy' perfused regions was 3.09 (range 2.083.90). These fractional ventilations can be compared with the values for ventilated lung of 1.95 found in 20 adults by Secker-Walker et al. (1973) and the values for perfused lung of $1 \cdot 68-2 \cdot 00$ found in 11 normal adults by Heckscher et al. (1966), using different methods. Theoretically, the fractional ventilation should resemble alveolar ventilation divided by end-expiratory lung volume. Using the mean data related to age collected by Godfrey (1974), this index is calculated to be 4.00 for the newborn infant, $3 \cdot 85$ for children between 1 and 5 years, and $2 \cdot 25$ for adults. These theoretical values are similar to those we found in children and others found in adults, and thus serve as some justification for the methods.

The distribution indices which we found in healthy regions were usually close to the ideal value of 1.0 (e.g. left lower zone in Case 6, Table II) and this agrees with the results in normal lungs found by Treves et al. (1974). Their fractional ventilation indices appear to have been normalized for whole lung clearance and cannot be compared with our values or with the likely values based on alveolar ventilation and lung volume.

The value of the ${ }^{13} \mathrm{~N}$ studies in the individual patients is largely self-evident from the results, and will not be discussed in detail. It seems that the test is most useful in defining the extent of a known abnormality (e.g. Case 2 ) or showing the localization of an abnormality (e.g. Cases 3, 5, and 6), but can also help in differential diagnosis (Cases 7 and 8) and even in showing healthy lung tissue (Cases 1 and 4). Though the bulk distribution of gas and blood were useful indices in some cases ( 3 and 6 ), the demonstration of gas trapping and hence poor ventilation-perfusion relations was often the most helpful finding (e.g. Cases 2, 7, and 8). This emphasizes the need for both inhalation and perfusion studies.

Finally, we recommend the use of ${ }^{13} \mathrm{~N}$, which is a more physiological radioisotope tracer than ${ }^{133} \mathrm{Xe}$ because of its very low solubility. Its safety of handling due to its short half-life is an additional advantage. The major disadvantage is of course that it can only be used in an institute where there is a cyclotron on site. The number of medical cyclotrons around the world has now reached 14 (Glass, 1973). Our technique could be adapted to use ${ }^{133} \mathrm{Xe}$, but the computation of results is likely to be more difficult because of tissue solubility. We have subsequently studied a further 21 infants and children using the bolus technique and have confirmed the clinical value of the method as illustrated in these first 8 patients.

We are grateful to our colleagues in the Medical Research Council Cyclotron Unit for help in performing these studies, and especially to Mr. P. Buckingham. We also thank Drs. E. N. Hey, E. Shinebourne, and D. Lawson for referring their patients to us for investigation. We have benefitted from the advice of a number of colleagues and would particularly like to thank Drs. J. M. B. Hughes, J. B. West, and P. Winlove.

This work was partly supported by an MRC grant to one of us (H.G.).

\section{REFERENCES}

Ball, W. C., Stewart, P. B., Newsham, L. G. S., and Bates, D. V. (1962). Regional pulmonary function studied with xenon ${ }^{133}$. fournal of Clinical Investigation, 41, 519.

Fowler, W. S., Cornish, E. R., and Kety, S. S. (1952). Lung function studies, VIII. Analysis of alveolar ventilation by pulmonary $\mathrm{N}_{2}$ clearance curves. Fournal of Clinical Investigation, 31, 40.

Glass, H. I. (1973). New applications of radiopharmaceuticals labelled with cyclotron-produced radionuclides. Medical Radiosotope Scintigraphy, vol. 2. International Atomic Energy Agency, Vienna. 
Glass, H. I., and de Garreta, A. C. (1971). The quantitative limitations of exponential curve fitting. Physics in Medicine and Biology, 16, 119.

Godfrey, S. (1974). Growth and development of the respiratory system. Scientific Foundations of Paediatrics, p. 254. Ed. by J. A. Davis and J. Dobbing. Heinemann, London.

Godfrey, S., Ronchetti, R., Stocks, J., and Hallidie-Smith, K. (1975). Generalized pulmonary hyperinflation and Fallot's tetralogy in a neonate investigated by pulmonary physiological and radioisotopic methods. Thorax. (In the press).

Heckscher, T., Larsen, O. A., and Lassen, N. A. (1966). A clinical method for determination of regional lung function using intravenous injection of $\mathrm{Xe}^{133}$. Scandinavian fournal of Respiratory Diseases. Suppl. 62, p. 31.

Knipping, H. W., Bolt, W., Venrath, H., Valentin, H., Ludes, H., and Endler, P. (1955). Eine neue methode zur prüfung der herz- und lungenfunktion. Deutsche medizinische Wochenschrift, 80, 1146.

Koch, G., Heiskanen, T., Riihimäki, E., Lind, J., Tähti, E., and Osterlund, K. (1973). Regional distribution of ventilation and perfusion in the healthy newborn infant and in the idiopathic respiratory distress syndrome. Bulletin de Physio-Pathologie Respiratoire, 9, 1511.

Macleod, W. M. (1954). Abnormal transradiancy of one lung. Thorax, $8,147$.
Ronchetti, R., Benci, S., Federici, E., Manfredi, M., Ciofetta, L., and Gentili, G. (1974). Theoretical bases for the calculation of the regional ventilation/perfusion ratio $(\dot{\mathrm{V}} / \dot{\mathrm{Q}})$ of the lung in the newborn. Fournal of Nuclear Biology and Medicine, $18,123$.

Ronchetti, R. Geubelle, F., Chantraine, J. M., and Senterre, J. (1971). Studio del rapporte ventilazione/perfusione nel neonato mediante lo $\mathrm{Xe}^{333}$. Minerva Pediatrica, 23, 1476.

Secker-Walker, R. H., Hill, R. I., Markham, J., Baker, J., Wilhelm, J., Alderson, P. O., and Potchen, E. J. (1973). The measurement of regional ventilation in man: a new method of quantitation. Fournal of Nuclear Medicine, 14, 725.

Seltzer, R. A., Keriakes, J. G., and Saenger, E. L. (1964). Radiation exposure from radioisotopes in pediatrics. New England Fournal of Medicine, 271, 84.

Treves, S., Ahnberg, D. S., Laguarda, R., and Strieder, D. J. (1974). Radionuclide evaluation of regional lung function in children. Fournal of Nuclear Medicine, 15, 582.

Correspondence to Dr. S. Godfrey, Department of Paediatrics and Neonatal Medicine, Hammersmith Hospital, Du Cane Road, London W12 0HS. 